\title{
Two-Dimensional River Flow Patterns Observed with a Pair of UHF Radar System
}

\author{
Yidong Hou, Biyang Wen, Yonghuai Yang, Jing Yang, and Caijun Wang
}

Electronic Information School, Wuhan University, Wuhan 430072, China

Correspondence should be addressed to Yidong Hou; houyidong@whu.edu.cn

Received 7 November 2016; Revised 15 March 2017; Accepted 30 March 2017; Published 20 April 2017

Academic Editor: Diego Masotti

Copyright ( 2017 Yidong Hou et al. This is an open access article distributed under the Creative Commons Attribution License, which permits unrestricted use, distribution, and reproduction in any medium, provided the original work is properly cited.

\begin{abstract}
A pair of ultrahigh-frequency (UHF) radars system for measuring the two-dimensional river flow patterns is presented. The system consists of two all-digital UHF radars with exactly the same hardware structure, operating separately at $329-339 \mathrm{MHz}$ and 341-351 MHz. The adoption of direct radio frequency (RF) sampling technique and digital pulse compression simplifies the structure of radar system and eliminates the distortion introduced by the analog mixer, which improves the SNR and dynamic range of the radar. The field experiment was conducted at Hanjiang River, Hubei province, China. Over a period of several weeks, the radar-derived surface velocity has been very highly correlated with the measurements of EKZ-I, with a correlation coefficient of 0.958 and a mean square error of $0.084 \mathrm{~m} / \mathrm{s}$.
\end{abstract}

\section{Introduction}

Monitoring the river flow velocity serves as an important part in the field of flood control, waterborne freight, fisheries, and so on. Conventionally, it is measured using the method of river buoy, rotor current meter, ADCP, and electromagnetic flow meter. However, these instruments have to contact with the water directly, bringing much pressure on their placement and maintenance, and require more professional and high technological operators. Besides, these methods are of singlepoint measurement, which hardly get the flow field of the whole waters. All these challenges have promoted the development of noncontact measurement. In the last decades, radar, an important noncontact measurement method, has been widely used in the measurement of ocean current and river flow. The development of high frequency (HF) and UHF radars has mainly undergone three stages: theoretical basis, monitoring ocean current with HF radar, and river flow measurement using UHF radar.

Crombie [1] proposed the backscattering mechanism of ocean waves in 1955, and then in 1966, Wait [2] discovered and quantitatively explained that this backscattering mechanism is produced by the Bragg scattering between electromagnetic waves and half wavelength ocean waves. In 1972, the first- and second-order radar cross-section (RCS) equations were derived by Barrick [3, 4], which laid a theoretical foundation for monitoring ocean and river surface dynamic parameters using radar. After that, Lipa and Barrick [5-7] pioneered efforts to derive ocean information from the HF spectra. Following their lead, HF radar has been widely studied with fruitful results. Several representative HF radar systems including SeaSonde, Wellen Radar (WERA), Ocean Surface Current Radar (OSCR), Ground Wave Radar (GWR), and Ocean State Monitoring and Analysis Radar (OSMAR) have come out one after another. The SeaSonde system using a crossed-loop/monopole as receiving antenna array not only has outstanding performance, but also has the advantages of compact structure, small size, and low cost $[8,9]$. Compared with the SeaSonde, the WERA system in Germany uses an array receiving antenna, which has more flexible spatial resolution [10]. The OSCR system in the UK is evolved from the SeaSonde system, which is mainly used to measure the ocean current with high accuracy in the near distance [11]. The GWR system developed in Canada in 1990, using the peak power of $16 \mathrm{KW}$, is a large array radar which has been not only used to monitor the ocean state, but also mainly used to detect ships, icebergs, and so on [12]. The OSMAR system was developed by Wuhan University in 1987, and so far there are three versions which are array radar (OSMAR2000), portable 


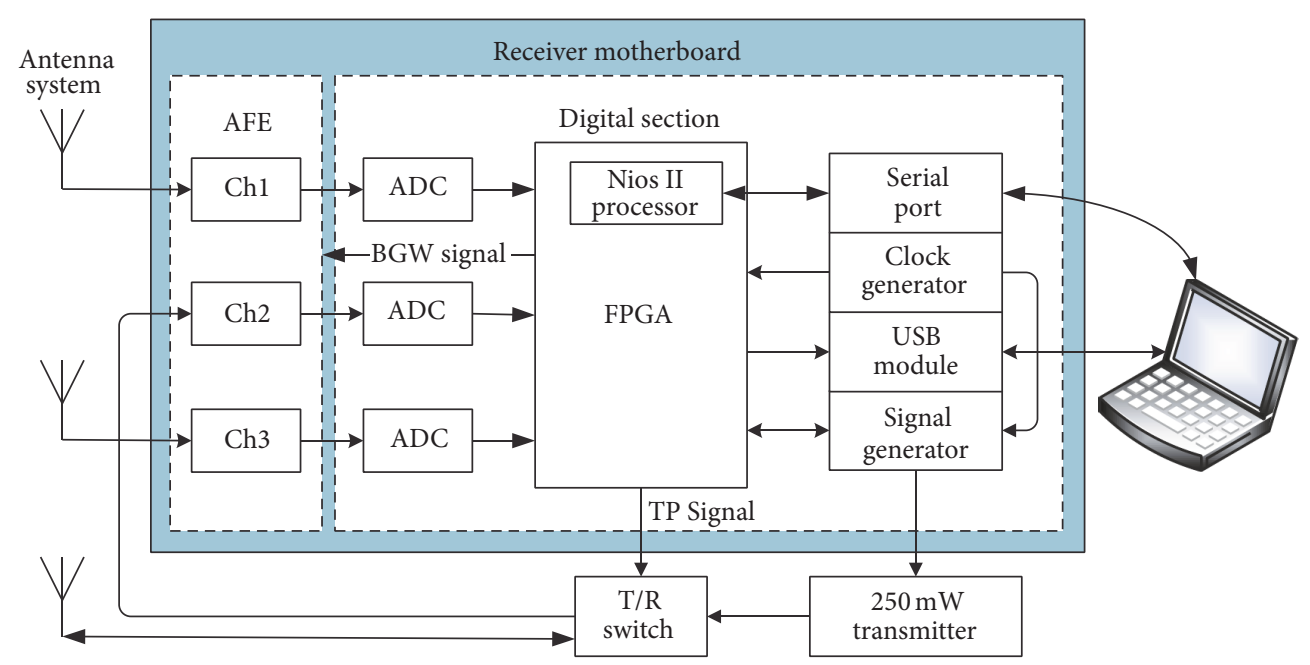

FIgURE 1: OSMAR-SU system structure.

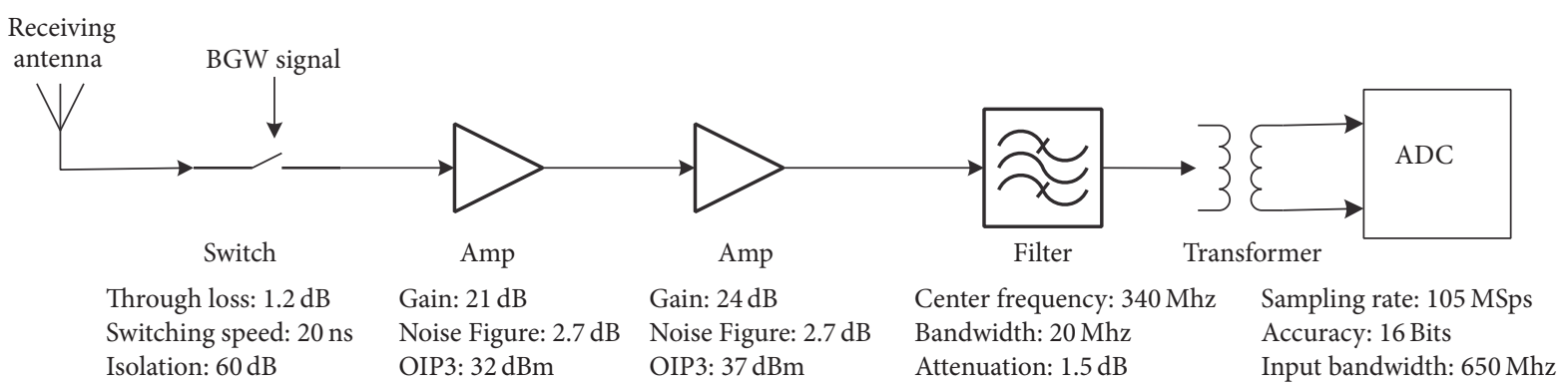

FIgURE 2: AFE and ADC architecture.

radar (OSMAR-S), and dual-frequency radar (OSMAR-SD), respectively $[13,14]$.

The success of HF radar in monitoring the ocean state has promoted the development of the measurement of river surface dynamic parameters with UHF radar. Randell et al. [15] measured the ocean clutter characteristics using coherent Doppler UHF radar in 2000. Based on the SeaSonde system, CODAR developed the UHF radar system (RiverSonde) to measure the river surface flow and has carried out several field experiments to verify its high performance [16-19]. Wuhan University has been devoted to the research of noncontact measurement for river flow monitoring since 2004 and successfully designed its first UHF radar based on the OSMAR system in 2005 [20]. After years of development, Wuhan University finally designed its first all-digital UHF radar system USDPR in 2013, along with a lot of experiments that demonstrated its excellent performance [21-23].

OSMAR-SU is the latest generation of all-digital UHF radar developed by Wuhan University, whose structure is more simplified and the radar performance gets further improved with the application of direct RF sampling, digital pulse compression, and transmit-receive sharing technology. In this paper, we will describe the structure of OSMAR-SU and the realization of all modules in detail in Section 2. The radar waveform parameters and signal processing methods are presented in Section 3. The field experiment and the comparisons of results are described in Sections 4 and 5, respectively. Conclusion is presented in Section 6.

\section{The Radar Structure and Realization of All Modules}

Figure 1 shows the structure of OSMAR-SU. There are five sections, antenna system, receiver motherboard, TransmitReceive switch (T/R switch), small power transmitter, and Industrial Personal Computer (IPC). In this radar system, direct RF sampling is utilized to realize the pulse compression in digital domain, so the structure is greatly simplified.

2.1. Receiver Motherboard. OSMAR-SU employs a more compact structure, as Figure 1 shows. Almost all circuit modules, including analog front end (AFE), analog-to-digital converter (ADC), clock generator, signal generator, serial port, USB module, and FPGA, are integrated on the receiver motherboard. Thereinto, the architecture of AFE and ADC is shown in Figure 2. In the all-digital radar, the AFE only functions as amplifier and filter and no longer contains the mixer, which means that the distortion of nonlinear and intermodulation introduced by the mixer is completely eliminated, and the dynamic range of the receiver will be greatly improved. The linear gain and third-order intermodulation distortion (IMD3) of the AFE are measured as shown in 


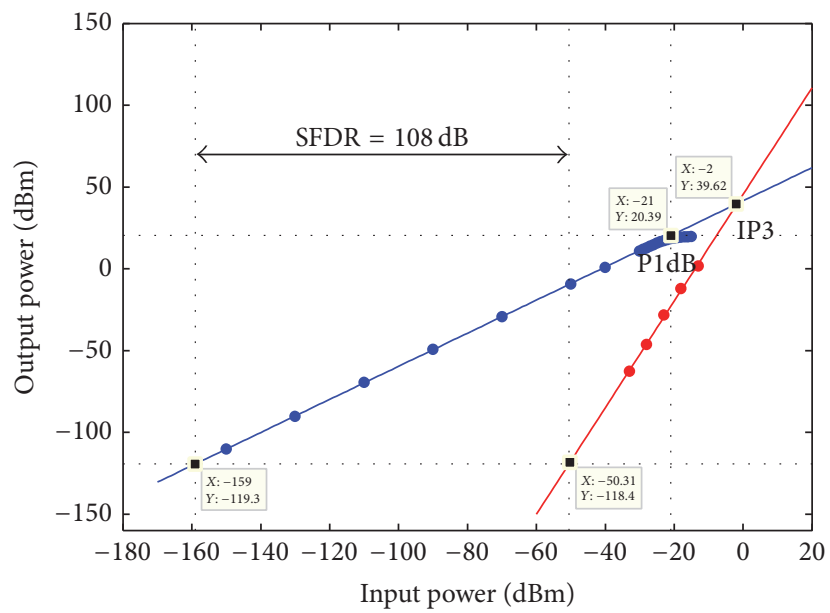

FIgURE 3: The linear gain and third-order intermodulation distortion (IMD3) of the AFE.

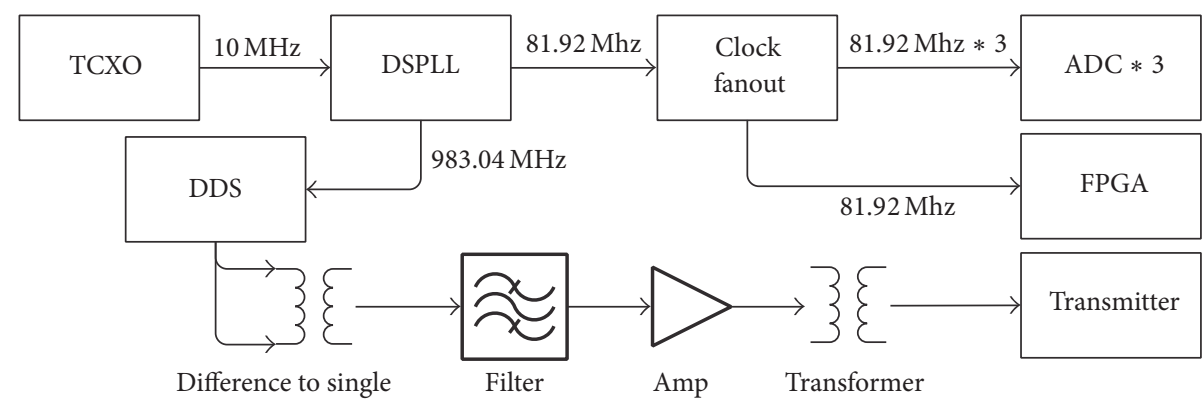

FIGURE 4: Clock and signal generator module.

Figure 3, and the measurement results indicate that the gain of the AFE is $40.7 \mathrm{~dB}$, the $1 \mathrm{~dB}$ compression point (P1dB) is $-21 \mathrm{dBm}$, the input 3rd-order intercept point (IIP3) is $-2 \mathrm{dBm}$, the sensitivity of $\mathrm{AFE}$ is $-159 \mathrm{dBm} / \mathrm{Hz}$, and the spurious free dynamic range (SFDR) is up to $108 \mathrm{~dB}$. In addition, the channel isolation and bandwidth of the AFE are $65 \mathrm{~dB}$ and $35 \mathrm{MHz}$, respectively.

Structure of clock and signal generator module is as Figure 4 shows. Temperature compensated crystal oscillator (TCXO) as the clock source of the system output $10 \mathrm{MHz}$. Two coherent clock signals are generated by digital signal phaselock loop (DSPLL), and their frequencies are $81.92 \mathrm{MHz}$ and 983.04 MHz. The clock (983.04 MHz) is used as a reference clock for signal generator, while the other clock $(81.92 \mathrm{MHz})$ is driven to 4 channels and is employed as the system clock for FPGA and the sampling clock for ADC separately. The signal generator consisting of direct digital synthesizer (DDS), RF filter, amplifier, and transformer is used to generate radar signal.

2.2. Antenna System and Transmitter. OSMAR-SU antenna system adopts uniform liner array (ULA). The array element spacing equals half wavelength, and the array consists of three five-element Yagi antennas. The beam width of the Yagi antenna is 90 degrees, and the detection range is between -70 and 70 degrees. The antenna, located in the middle of

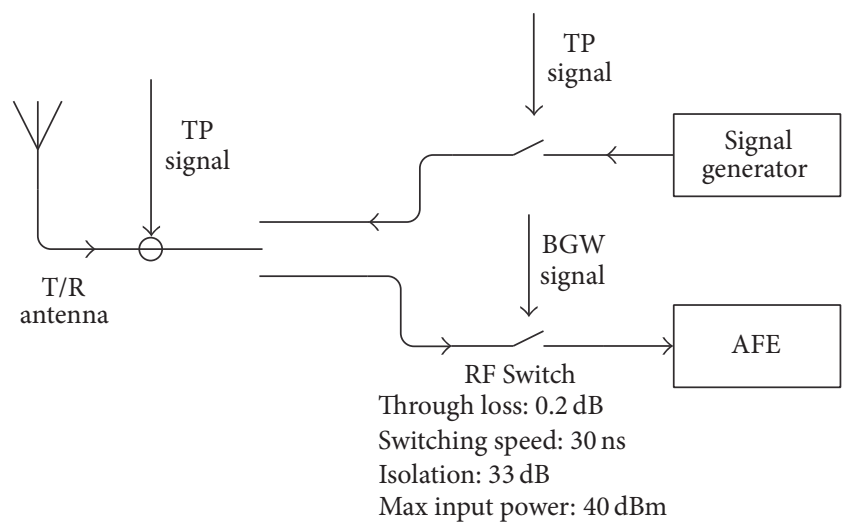

FIGURE 5: T/R switch architecture.

the array, is used as a common antenna for receiving and transmitting, and the radio frequency (RF) switch switches the T/R functions. The transmitter power of the OSMAR-SU is only $250 \mathrm{~mW}$. Table 1 lists more detailed parameters of the antenna and transmitter.

2.3. $T / R$ Switch. T/R switch architecture is shown as Figure 5. Single RF switch difficultly satisfies the requirement of isolation; therefore two RF switches are connected in series to 
TABLE 1: Parameters of transmitter and antenna.

\begin{tabular}{lccr}
\hline Transmitter & Value & Antenna & Value \\
\hline Gain & $24 \mathrm{~dB}$ & Gain & $7.5 \mathrm{dBi}$ \\
Frequency & $320-360 \mathrm{Mhz}$ & Flatness & $<2 \mathrm{~dB}$ \\
Flatness & $<1 \mathrm{~dB}$ & Impedance & $50 \mathrm{Ohm}$ \\
Output power & $24 \mathrm{dBm}$ & Polarization & Vertical \\
Noise figure & $3.45 \mathrm{~dB}$ & VSWR & $<2$ \\
OIP3 & $38 \mathrm{dBm}$ & Beam width & $90 \mathrm{Deg}$ \\
VSWR & $<1.5$ & Front-back Ratio & $>14 \mathrm{~dB}$ \\
\hline
\end{tabular}

TABLE 2: OSMAR-SU waveform parameters.

\begin{tabular}{lcc}
\hline Parameter & Site A & Site B \\
\hline Carrier frequency & $334 \mathrm{MHz}$ & $346 \mathrm{MHz}$ \\
Transmitting power & $250 \mathrm{~mW}$ & $250 \mathrm{~mW}$ \\
Bandwidth & $10 \mathrm{MHz}$ & $10 \mathrm{MHz}$ \\
Frequency-sweeping time width & $40 \mathrm{~ms}$ & $40 \mathrm{~ms}$ \\
Frequency-sweeping period & $41 \mathrm{~ms}$ & $41 \mathrm{~ms}$ \\
Pulse repetition frequency & $300 \mathrm{KHz}$ & $300 \mathrm{KHz}$ \\
Maximum unambiguous range & $500 \mathrm{~m}$ & $500 \mathrm{~m}$ \\
Range resolution & $15 \mathrm{~m}$ & $15 \mathrm{~m}$ \\
Maximum unambiguous velocity & $5.489 \mathrm{~m} / \mathrm{s}$ & $5.268 \mathrm{~m} / \mathrm{s}$ \\
Velocity resolution & $0.0214 \mathrm{~m} / \mathrm{s}$ & $0.0206 \mathrm{~m} / \mathrm{s}$ \\
\hline
\end{tabular}

realize a relatively high isolation. Transmitting and receiving status shifting of $T / R$ switch are controlled by a pair of complementary signals of transmitting pulse (TP) signal and bating ground wave (BGW) (defined as receiving pulse) signal. The $T / R$ switch achieves a high isolation of $66 \mathrm{~dB}$, a fast switching time of $30 \mathrm{~ns}$, and a high input power of $40 \mathrm{dBm}$.

\section{Waveform Parameters and Signal Processing Algorithm}

3.1. Waveform Parameters Design. OSMAR-SU adopts Frequency Modulated Interrupting Continuous Wave (FMICW) mechanism, and the waveform parameters can be configured according to the requirements of the experimental environment. In order to avoid the mutual interference between the two OSMAR-SUs, the central frequencies of the two radars are $334 \mathrm{MHz}$ and $346 \mathrm{MHz}$. The signal bandwidth is $10 \mathrm{MHz}$; that is to say, two radars operate at $329-339 \mathrm{MHz}$ and 341-351 MHz, respectively. All the other waveform parameters are consistent, and detailed parameters are shown in Table 2. Based on Barrick's theory [3], it is deduced that $334 \mathrm{MHz}$ and $346 \mathrm{MHz}$ correspond to the water wave velocity of $0.837 \mathrm{~m} / \mathrm{s}$ and $0.822 \mathrm{~m} / \mathrm{s}$; therefore the maximum flow velocities that can be measured by the two radars are, respectively, $4.652 \mathrm{~m} / \mathrm{s}$ and $4.446 \mathrm{~m} / \mathrm{s}$. There is no need to consider the problem of blind area, since the radars are located close to the river bank. In a pulse interrupt cycle, the receiving cycle starts immediately after the end of the transmitting cycle.
3.2. Signal Processing Algorithm. Signal processing flow of OSMAR-SU is shown in Figure 6. The range spectrum is obtained from echo signal through bandpass sampling, deramp (digital mixing), cascaded integrator-comb (CIC) filter, finite impulse response (FIR) filter, and fast Fourier transform (FFT), which is an equivalent pulse compression process. After digital pulse compression and FFT, Doppler spectrum is obtained, which include first-order Bragg peaks and noise. The first-order peaks are separated from noise by absorbance subtraction method; then direction of arrival (DOA) for every Doppler frequency-point in the first-order peaks is estimated through MUSIC algorithm [24]. Next, utilizing the frequency offset of Doppler spectral peaks with Bragg frequency, the actual flow velocity of a certain point in the river is calculated. After interpolating and smoothing, radial flow field is obtained from rough results. Finally, two radial flow fields are applied to synthesize two-dimensional flow pattern. Before DOA estimations, it is necessary to calibrate the array. This paper adopts active calibration method, placing an emission source in front of the array to calibrate its amplitude and phase.

The Doppler spectra are broadened by the radial flow of different directions to varying degrees. The relationship between the maximum Doppler shift and the maximum radial flow can be expressed as

$$
F_{V_{\max }}=\frac{2 V_{\max }}{\lambda}+F_{\text {Bragg }}
$$

where $F_{V_{\max }}$ is the maximum Doppler shift, $V_{\max }$ is the maximum radial river flow, $\lambda$ is the wavelength of radar signal, 


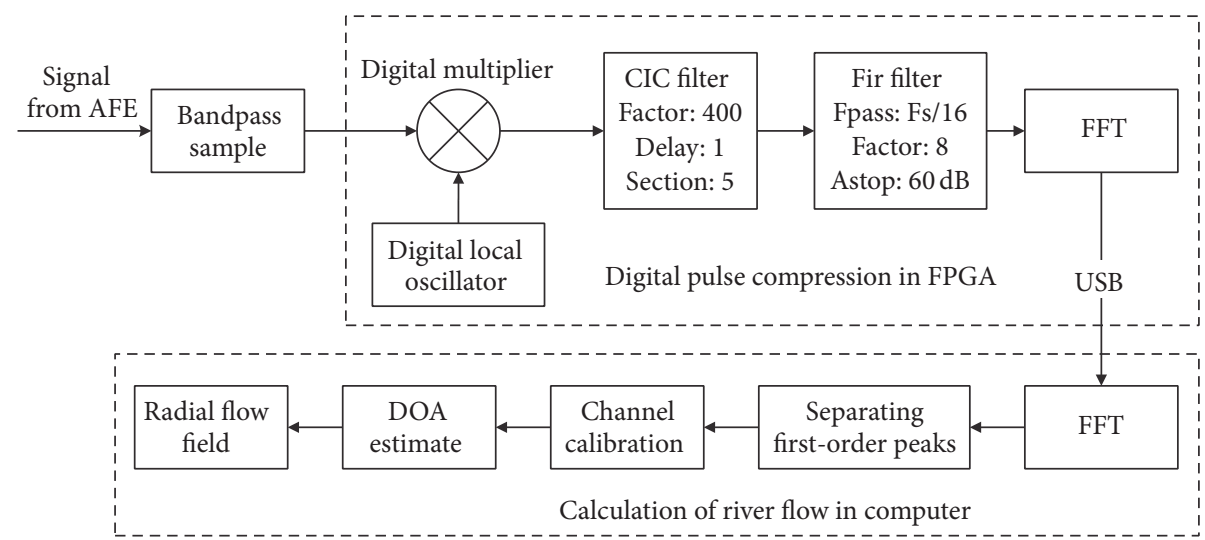

FIGURE 6: Signal processing flow.

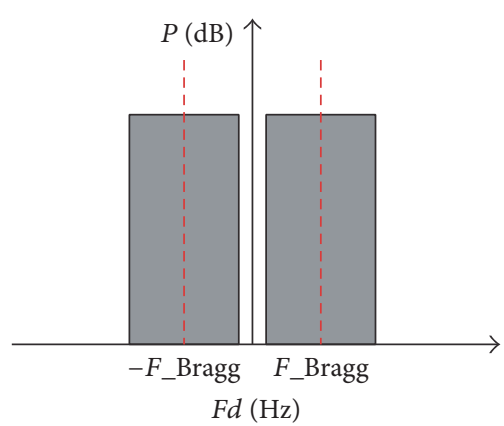

(a) $F_{V_{\max }}<2 F_{\text {Bragg }}$

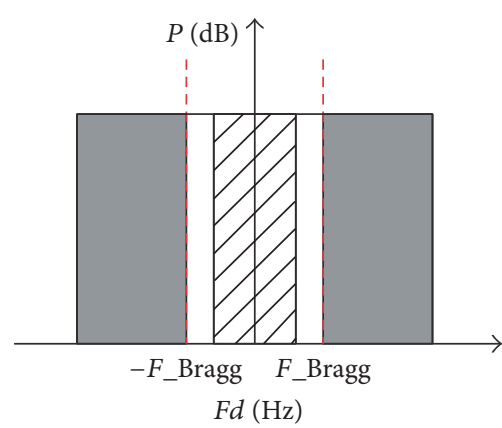

(b) $2 F_{\text {Bragg }}<F_{V_{\max }}<3 F_{\text {Bragg }}$

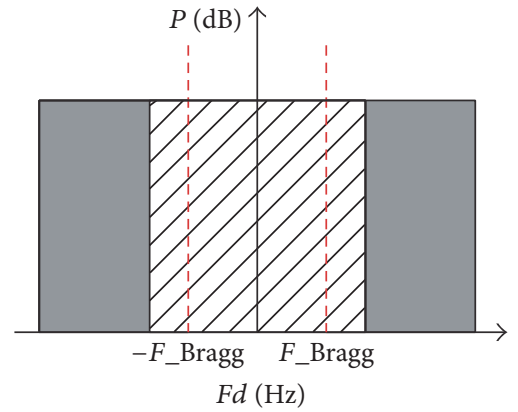

(c) $F_{V_{\max }}>3 F_{\text {Bragg }}$

FIGURE 7: Doppler-broadened spectra in varying degrees.

and $F_{\text {Bragg }}$ is the Bragg shift. There are three cases in the actual DOAs and radial flow estimation, which are

$$
\begin{aligned}
& \text { case } 1: F_{V_{\max }}<2 F_{\mathrm{Bragg}} ; \\
& \text { case 2: } 2 F_{\mathrm{Bragg}}<F_{V_{\max }}<3 F_{\mathrm{Bragg}} ; \\
& \text { case 3: } F_{V_{\max }}>3 F_{\mathrm{Bragg}} .
\end{aligned}
$$

For case 1, as shown in Figure 7(a), there is no aliasing between the positive and negative Bragg echoes. The firstorder Doppler-broadened peaks are selected in $\left[-F_{V_{\max }}\right.$, $\left.F_{V_{\max }}-2 F_{\text {Bragg }}\right]$ and $\left[2 F_{\text {Bragg }}-F_{V_{\max }}, F_{V_{\max }}\right]$ as shown as the dark areas in the Figure $7(\mathrm{a})$, and then the DOAs of Doppler shifts can be estimated by the classic MUSIC algorithm, and the radial flow can be computed by (1).

When the maximum radial flow is more than $0.82 \mathrm{~m} / \mathrm{s}$ (Bragg-wave velocity) and less than $1.64 \mathrm{~m} / \mathrm{s}$, the positive and negative Bragg echoes overlap, but the aliasing areas do not exceed $\left[-F_{\text {Bragg }}, F_{\text {Bragg }}\right]$. We call case 2 partial aliasing, as shown in Figure $7(\mathrm{~b})$. The intervals $\left[-F_{V_{\max }},-F_{\mathrm{Bragg}}\right]$ and $\left[F_{\text {Bragg }}, F_{V_{\max }}\right]$, as shown as the dark areas in the Figure $7(\mathrm{~b})$, are selected as the first-order Doppler-broadened peaks, because these two intervals completely contain the flow toward the radar and the flow away from the radar, respectively.
From case 1 and case 2, we can see that the classic MUSIC algorithm can unambiguously estimate the DOAs under the condition that the maximum radial flow is less than $1.64 \mathrm{~m} / \mathrm{s}$; nevertheless, the aliasing areas between the positive and negative Bragg echoes in case 3 will exceed $\left[-F_{\text {Bragg }}, F_{\text {Bragg }}\right]$, as shown in Figure 7(c). The same intervals as case 2 are still selected as the first-order Doppler-broadened peaks. Obviously, there are aliasing areas in the selected intervals. Since the echoes in the aliasing areas are coherent, the classic MUSIC algorithm cannot unambiguously resolve the direction of the velocity. In view of this situation, the five backup receiving channels reserved in OSMAR-SU will come in handy. The eight-element linear array and the spatial smoothing technique $[25,26]$ will be used to unambiguously estimate the DOAs of Doppler shifts in the aliasing area.

Here we give the simulation results of case 3 as shown in Figure 8. We assume that the relationship between radial flow and direction of arrival (DOA) is described by

$$
V r=V \cos \left(\theta+\frac{\pi}{2}\right)
$$

where $V r$ is the radial river flow, $V$ is the mean river flow, and $\theta$ is the DOA. Let $V=3.5 \mathrm{~m} / \mathrm{s}(V>1.64$ belongs to the case 3 ) and the simulation of the Doppler spectrum is shown 


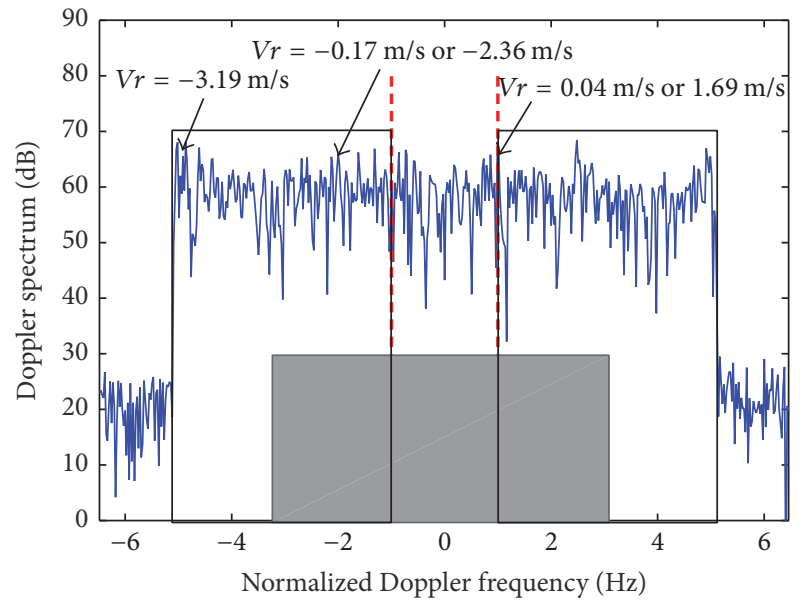

(a) The simulation of the Doppler spectrum

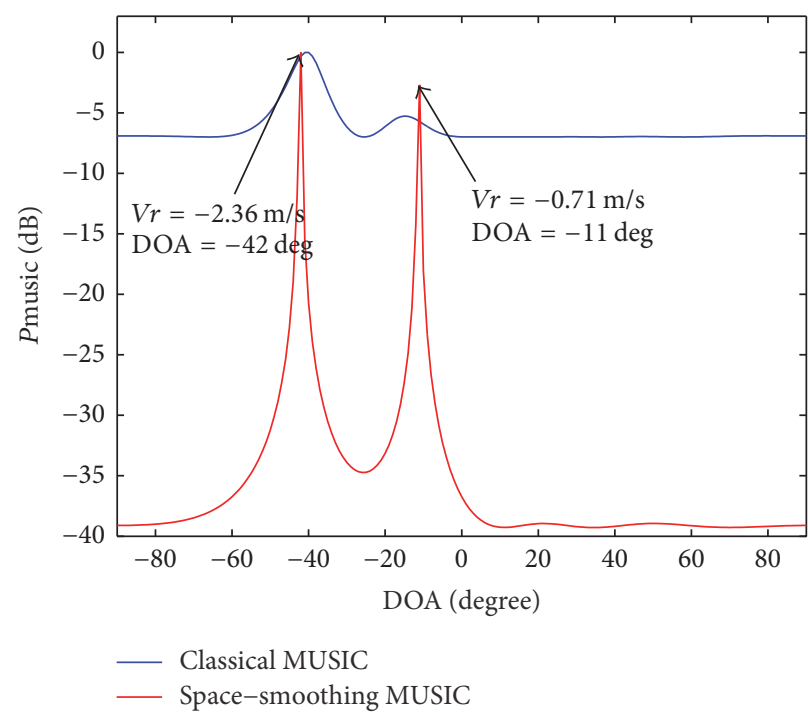

(c) MUSIC spectra at $-1.85 \mathrm{~Hz}$

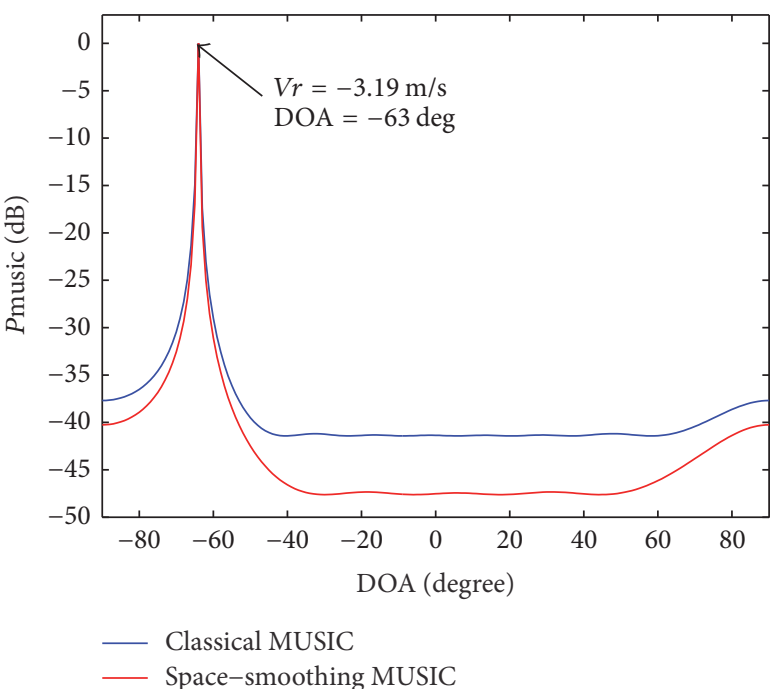

(b) MUSIC spectra at $-4.84 \mathrm{~Hz}$

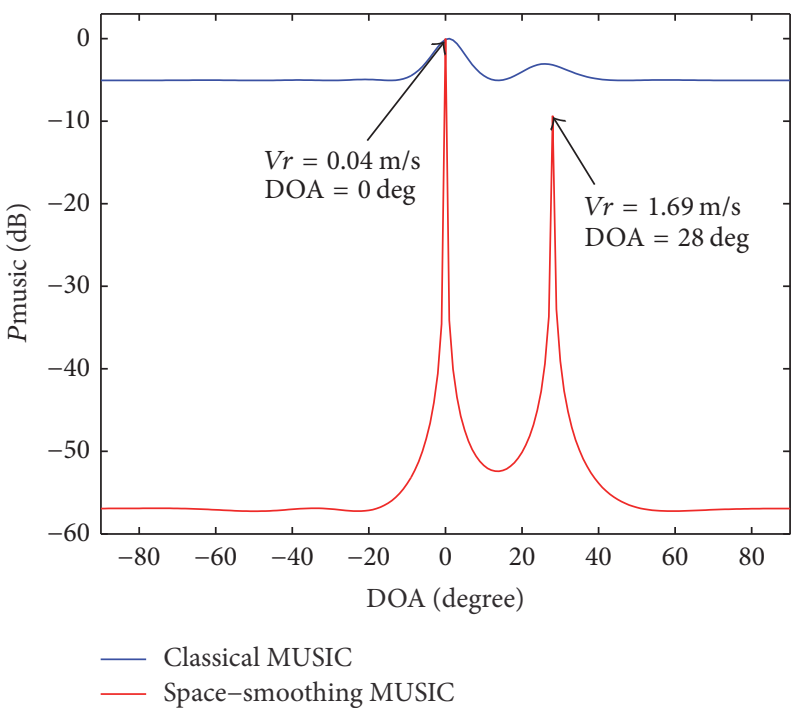

(d) MUSIC spectra at $1.04 \mathrm{~Hz}$

FIGURE 8: The simulation results of case 3.

in Figure 8(a), where the red dotted lines represent Bragg shifts, the gray shaded area represents the aliasing region, and the black box areas are selected for compute. We can see that the Doppler spectrum is severely broadened. We give the spatial spectra of three typical Doppler frequencies, as shown in Figures 8(b), 8(c), and 8(d). Thereinto, Figure 8(b) is in the outside of the aliasing region, while Figures 8(c) and $8(\mathrm{~d})$ are in the aliasing region. The simulation results indicate that

(1) The results of the classical MUSIC algorithm and those of the space-smoothing MUSIC algorithm are consistent if there is no aliasing.

(2) When aliasing occurs, the classical MUSIC algorithm will be invalid, while space-smoothing MUSIC still performs well.
(3) In the aliasing area, a relatively large DOA (absolute value) corresponds to a relatively large radial velocity (absolute value).

\section{Experiments}

In 2016, from July to August, a field experiment is implemented in the lower reaches of Hanjiang River. As the largest tributary of the Yangtze River, the width of the reach where the radars are located is about 300 meters. As is shown in Figure 9, the river flows from west to east; the radar field of view of Site A covers the river bend, while Site B monitors the straight channel, and the expected flow direction is shown as the yellow line in Figure 9. During the experiment, the radars successively suffered from concentrative rainfall and continuous high temperature weather but still received high 


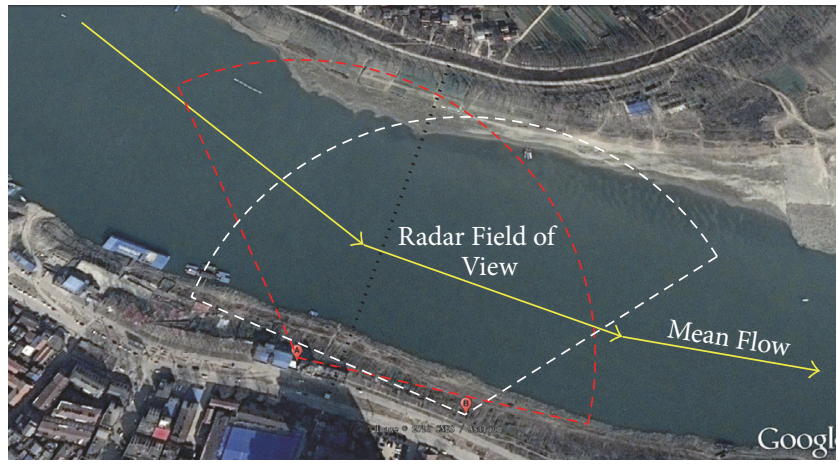

FIGURE 9: Schematic diagram of dual sites experiment.

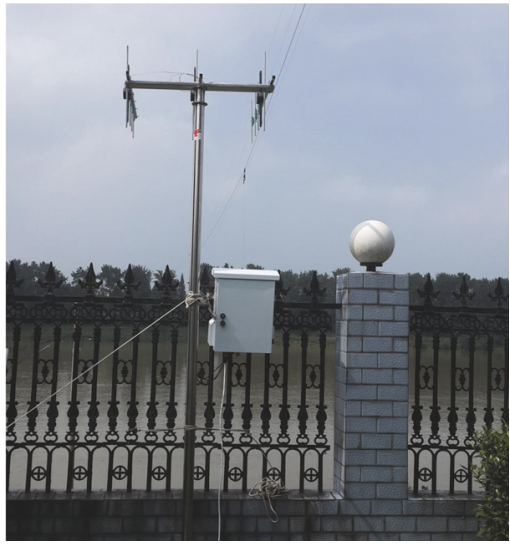

(a)

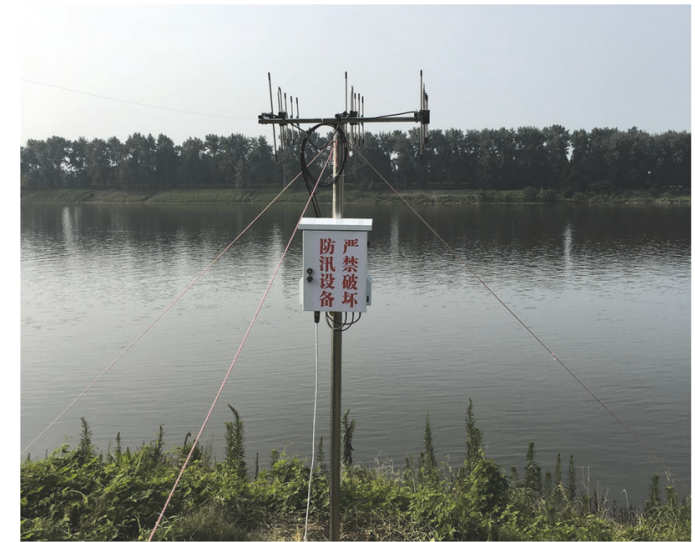

(b)

FIGURE 10: Dual OSMAR-SUs is deployed on the bank of Hanjiang River.

quality data. The preliminary experiments were conducted in flood period, and water level was high in the lower reaches of the Yangtze River, resulting in a relatively small flow velocity; the maximum surface flow velocity was about $0.7 \mathrm{~m} / \mathrm{s}$, while in the late experiment the water level dropped, and the maximum surface flow velocity climbed up to $1.2 \mathrm{~m} / \mathrm{s}$.

Figure 10 shows where and how the radars are deployed. The radar in Figure 10(a) is fixed in the yard of the hydrologic station close to the river bend with the antenna about $6 \mathrm{~m}$ above the water level. The other radar is fixed on the riverbank near the straight channel with the antenna about $5 \mathrm{~m}$ above the water level. Both radars are located on the same side of the river, about 155 meters apart. The radars look angle covers -70 to 70 degrees; to prevent the blind area between two sites, the normal of dual antenna array is shifted 20 degrees to the center. As is shown in Figure 9, the red and white sectors mark the field of view of the radars. The flow vector synthesis will be performed in the overlapping area. To compare, the flow measuring equipment EKZ-I records its observations. EKZ-I consists of cableway, lead fish and rotor flow meter. In Figure 9, the black dotted line marks where the cableway is, and the lead fish can cross the river along the cableway, so that it gets flow velocity at different distance from the offshore side.

\section{Results and Comparisons}

Figure 11 shows the Doppler-Range spectrum and the Doppler spectrum at $200 \mathrm{~m}$, and the SNR is about $40 \mathrm{~dB}$. Based on the first-order scattering equation of rough surface derived by Hickey et al. [12], the echo signal will be greatly enhanced when water wave and electromagnetic wave satisfy the resonance Bragg scattering. In this paper, the OSMARSU operates at $340 \mathrm{MHz}$, and corresponding Bragg resonance frequency is $1.88 \mathrm{~Hz}$. Due to the existence of water flow, the Doppler spectrum is broadened; the larger the flow velocity is, the more obviously it broadens.

Figure 12 shows the radial flow field of the two sites measured during the same time period. Figure 12(a) shows the result of Site A in the west, located at river bend where the flow direction is roughly from west to east. Due to the inertia of the river flow, the flow direction in this area is not perfectly along the river. Therefore, the radial flow velocity in front of the radar is not equal to $0 \mathrm{~m} / \mathrm{s}$. Figure 12(b) shows the result of Site B in the east, where the radar field of view is within the straight channel. The flow direction is from the left to the right of the radar along the river. The radial flow hence faces the radar on the left and the opposite on the right. The radial flow velocity in front of the radar is approximately equal to $0 \mathrm{~m} / \mathrm{s}$. 


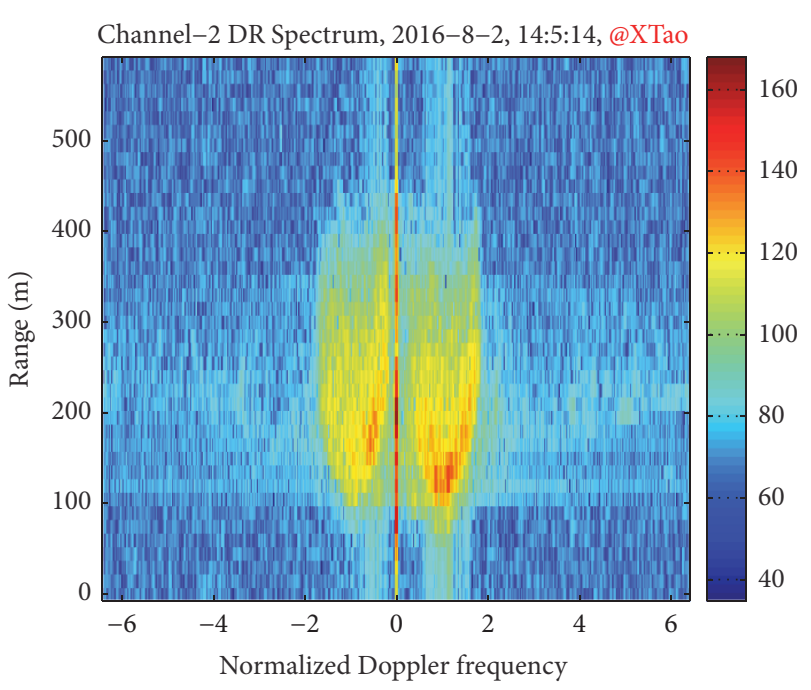

(a) Range-Doppler spectrum

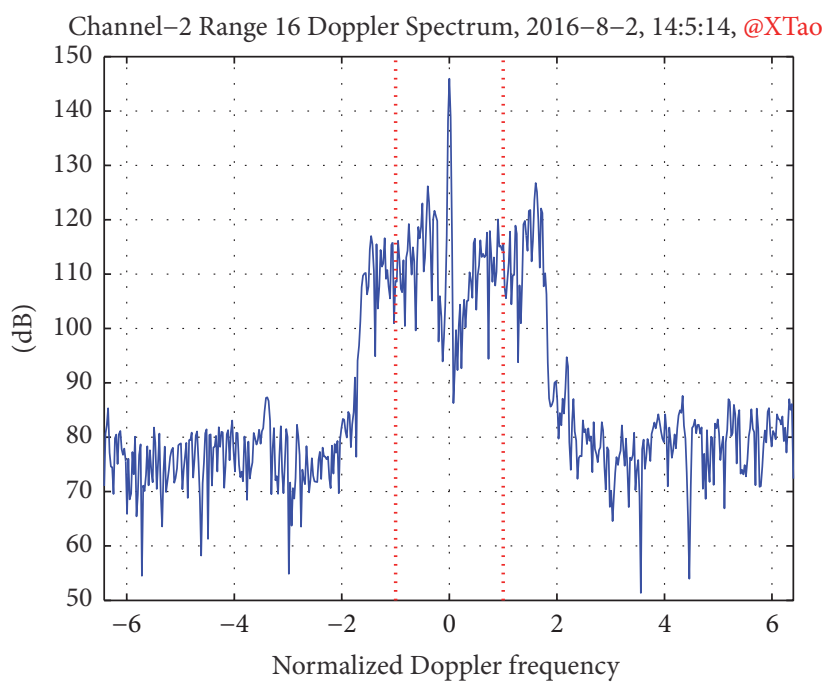

(b) Doppler spectrum

FIgURE 11: Echo Spectrum.

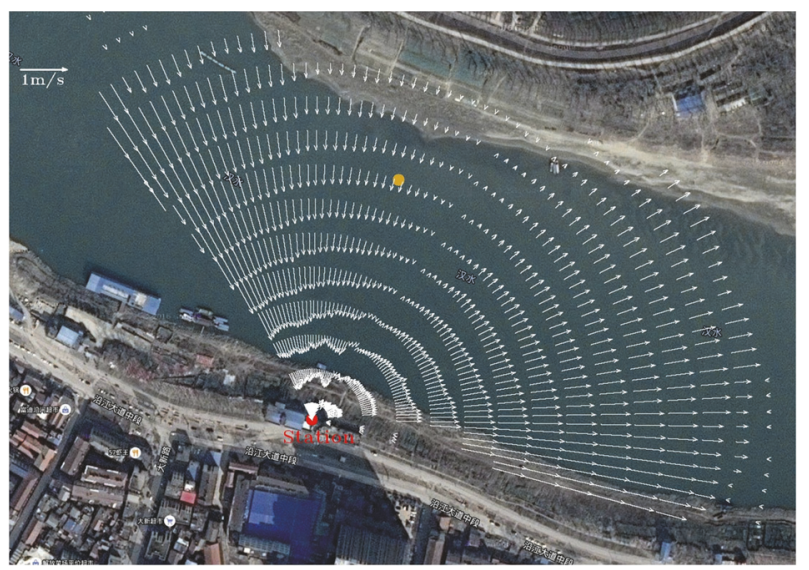

(a) Site A

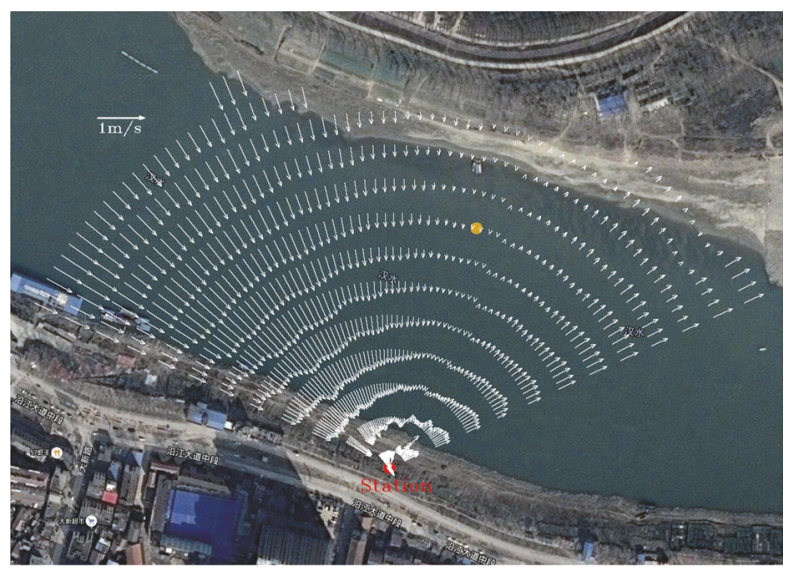

(b) Site B

FIGURE 12: At 2016-7-20-7:05, the radial flow field obtained by two radars.

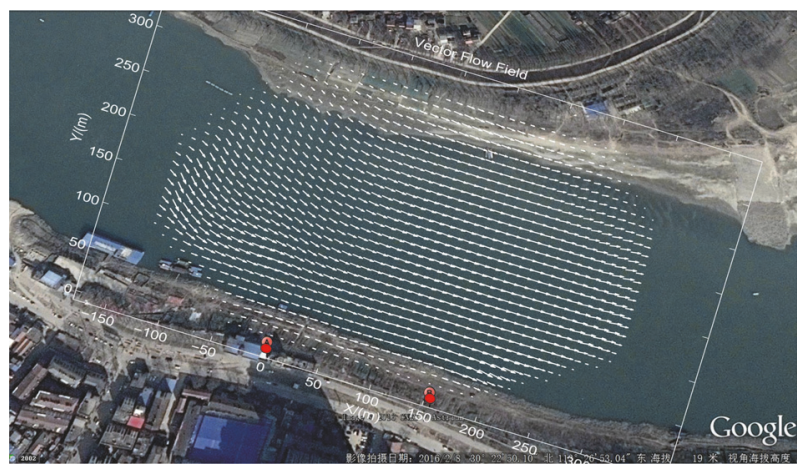

Figure 13: At 2016-7-24-7:05, two-dimensional flow pattern of the dual sites synthesized.

The radial flow field of the dual sites in Figure 12 is synthesized into two-dimensional flow pattern. As shown in Figure 13, the arrow direction represents the flow direction, and the arrow length represents the flow velocity. The flow direction obviously changes along the river. The closer to the shore, the smaller the flow velocity, which is in line with the actual situation. Flow velocities measured by EKZI and OSMAR-SU are compared as Figure 14 shows. The results of OSMAR-SU and EKZ-I have been highly correlated, with a correlation coefficient of 0.950 and a mean square error of $0.092 \mathrm{~m} / \mathrm{s}$. Also the result of dual sites system is better than single site system which has better accuracy in the straight channel (correlation coefficient 0.913, mean square error $0.102 \mathrm{~m} / \mathrm{s}$ ) than in the river bend (correlation coefficient 0.879 , mean square error $0.330 \mathrm{~m} / \mathrm{s}$ ). This indicates the measurement accuracy of the dual sites system is better than single site system in the river bend or more complex area.

From 2016-7-15 to 2016-7-30, nine comparison experiments between EKZ-I and OSMAR-SU are conducted and the results are shown in Figure 15, with a correlation coefficient of 0.958 , an average error of $0.033 \mathrm{~m} / \mathrm{s}$, and a mean 


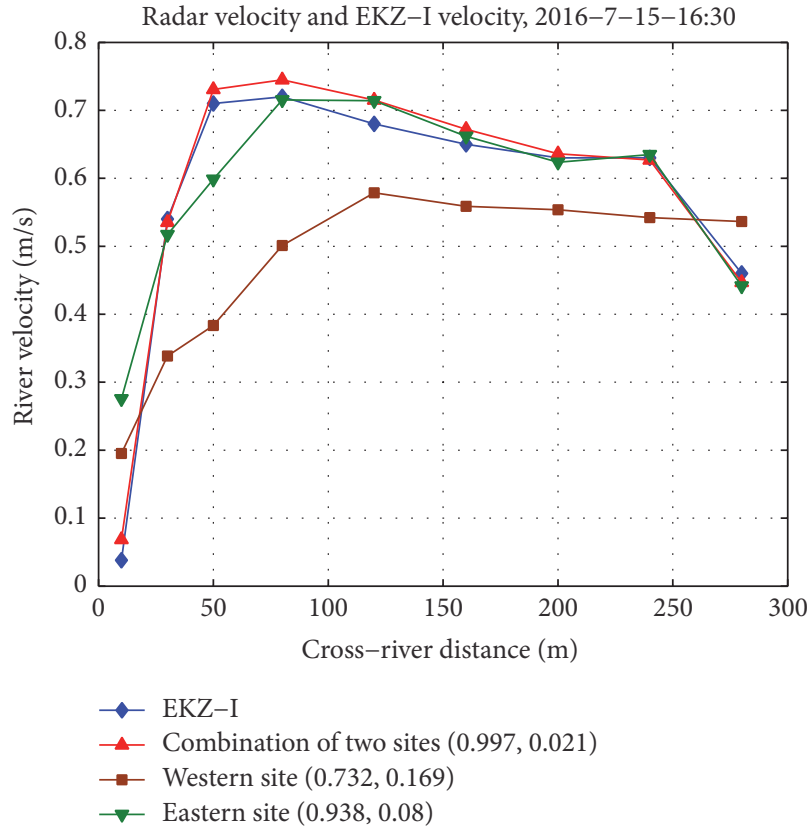

(a) $2016-7-15-16: 30$

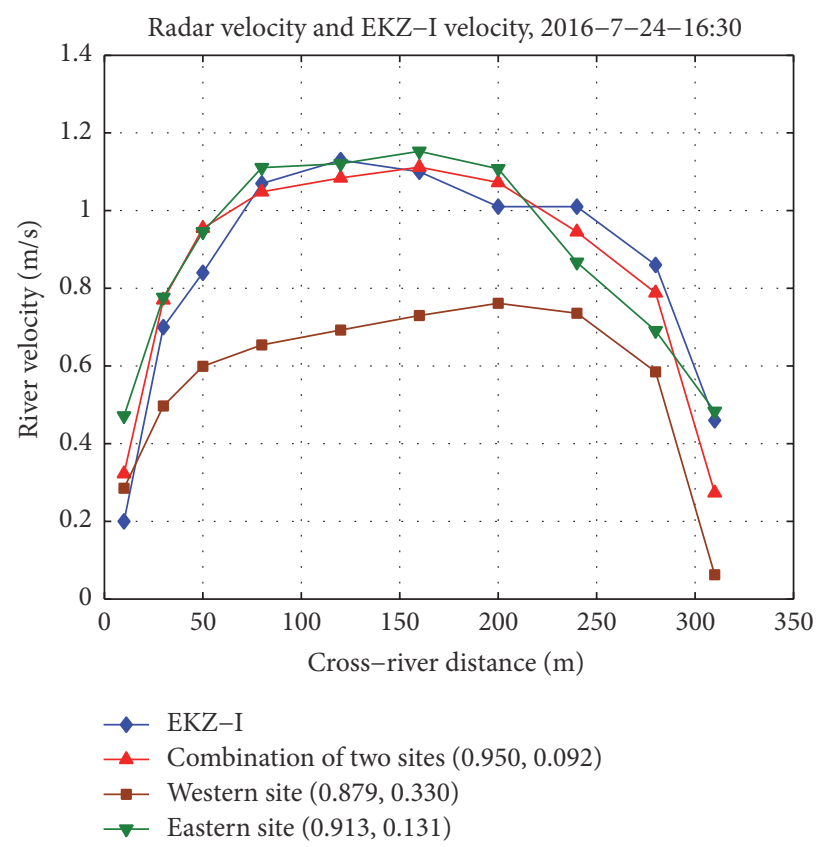

(b) 2016-7-24-16:30

FIGURE 14: The comparison of the results between OSMAR-SU and EKZ-I.

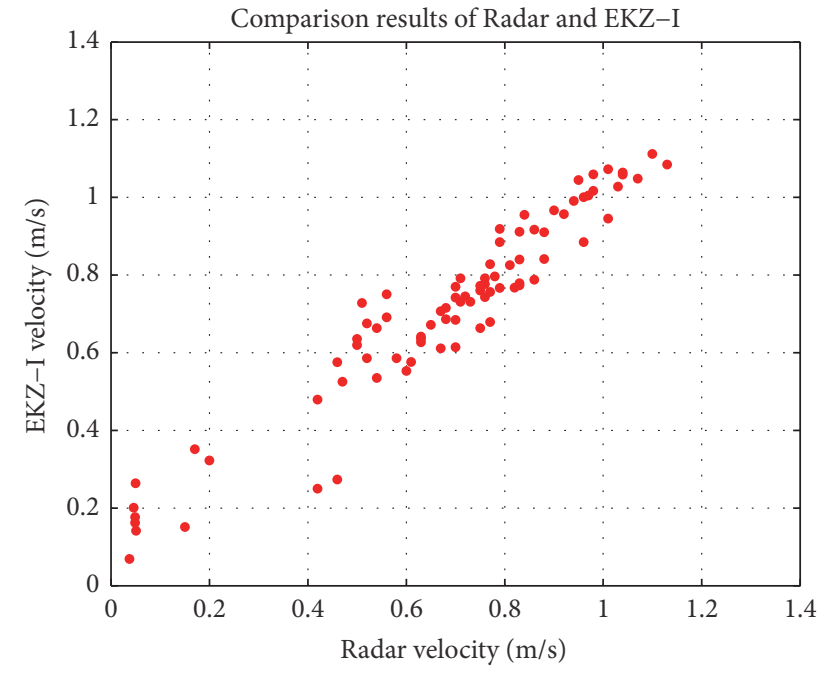

FIGURE 15: 2016-7-15 to 2016-7-30, 9 comparisons of the results between EKZ-I and OSMAR-SU.

square error of $0.084 \mathrm{~m} / \mathrm{s}$. Figure 16 is the two-dimensional flow pattern measured with previous generation of UHF radar (USDPR) designed by Wuhan University at 2014-8-13 in the same location. One radar antenna array was split into two units, $57 \mathrm{~m}$ apart, using transmission power of $10 \mathrm{~W}$. More details of the experiment can be found in [23]. It can be inferred from Figure 16 that single site measurement results (correlation coefficient 0.952 , mean square error $0.091 \mathrm{~m} / \mathrm{s}$ ) are more accurate than the results of the dual sites (correlation coefficient 0.910 , mean square error $0.158 \mathrm{~m} / \mathrm{s}$ ), and the
TABLE 3: Comparisons between OSMAR-SU and USDPR.

\begin{tabular}{lcc}
\hline Parameters & OSMAR-SU & USDPR \\
\hline Frequency & $340 \mathrm{MHz}$ & $340 \mathrm{MHz}$ \\
Power & $0.25 \mathrm{~W}$ & $10 \mathrm{~W}$ \\
Average error & $0.033 \mathrm{~m} / \mathrm{s}$ & $0.087 \mathrm{~m} / \mathrm{s}$ \\
Correlation & 0.985 & 0.910 \\
RSME & $0.084 \mathrm{~m} / \mathrm{s}$ & $0.158 \mathrm{~m} / \mathrm{s}$ \\
Comparison instrument & EKZ-I & EKZ-I \\
\hline
\end{tabular}

detection range of USDPR is much smaller than OSMAR-SU. Table 3 lists some detailed comparisons of OSMAR-SU and USDPR, and the comparison results indicate that OSMARSU achieved a more accurate measurement with a lower transmitting power.

\section{Conclusion}

This paper presents a pair of all-digital UHF radars system (OSMAR-SU) for measuring the two-dimensional river flow patterns and describes in detail the hardware architecture, waveform parameters, and signal processing method of the radar. The application of direct RF sampling, digital pulse compression, and transmit-receive sharing technology greatly simplifies the structure of the radar and obviously improves dynamic range, sensitivity, and channel isolation of the receiver. In order to verify the performance of the OSMAR-SU, a two-site field experiment was conducted at Hanjiang River, Hubei province, China, in July 2016, and the measurement results of the radar are compared with those 


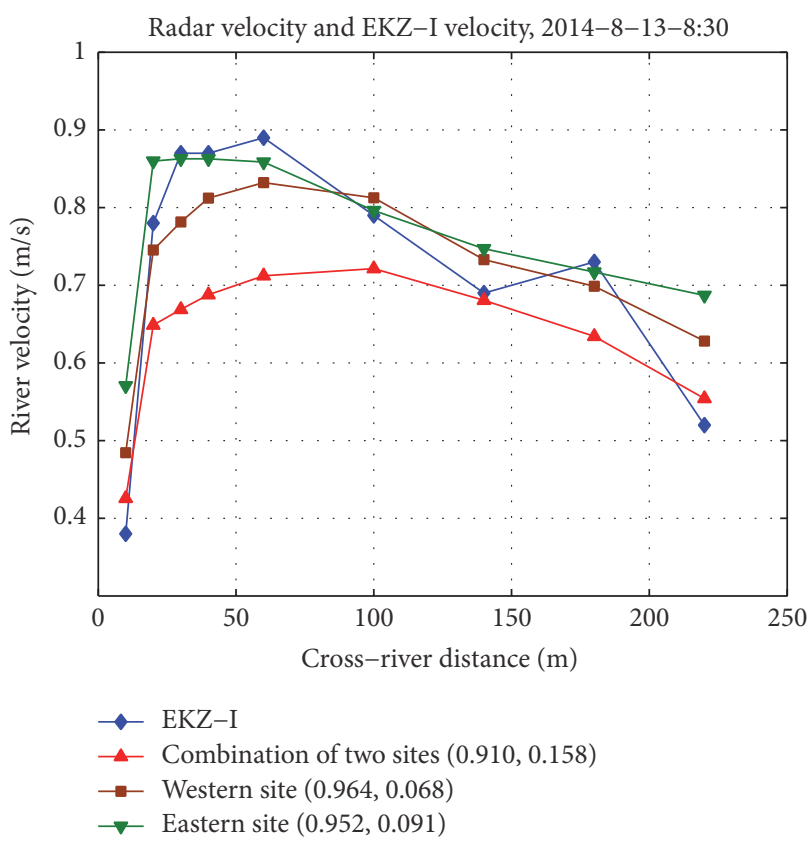

(a) Flow velocity comparisons

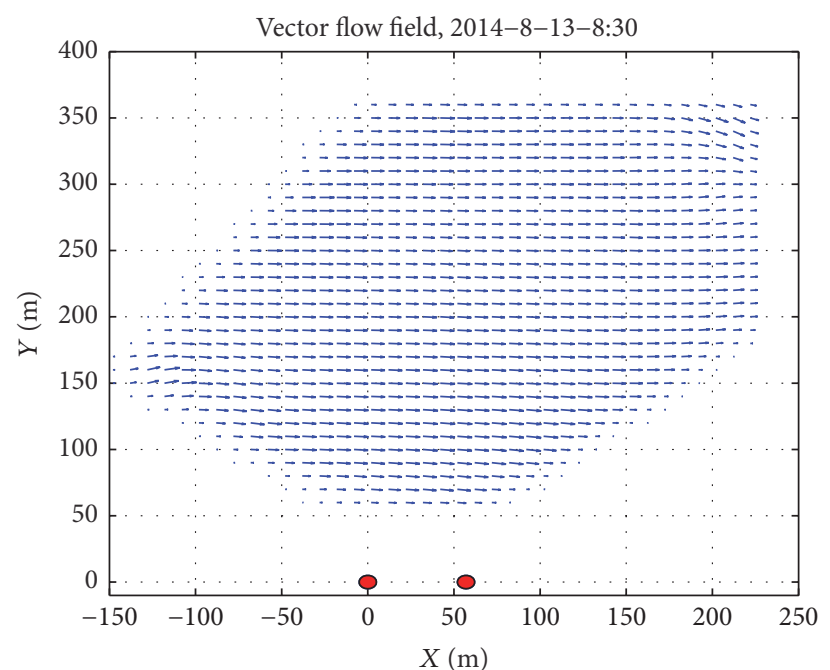

(b) Two-dimensional flow patterns

FIGURE 16: The comparison of the results between USDPR and EKZ-I.

of EKZ-I. The correlation is as high as 0.958 , and the mean square error is less than $0.084 \mathrm{~m} / \mathrm{s}$.

\section{Conflicts of Interest}

The authors declare that there are no conflicts of interest regarding the publication of this paper.

\section{Acknowledgments}

This work was supported by National Natural Science Foundation of China (Grant no. 61371198) and Natural Science Foundation of Hubei Province (Grant no. 2015CFB355). The authors would like to thank the staff of Hubei Xiantao hydrology station for helping them and providing high quality data.

\section{References}

[1] D. D. Crombie, "Doppler spectrum of sea echo at $13.56 \mathrm{Mc} . / \mathrm{s.}$." Nature, vol. 175, pp. 681-682, 1955.

[2] J. R. Wait, “Theories of Prolate Spheroidal Antennas," Radio Science, vol. 1, no. 4, pp. 475-512, 1966.

[3] D. E. Barrick, "First-order theory and analysis of MF/HF/VHF scatter from the sea," IEEE Transactions on Antennas and Propagation, vol. 20, no. 1, pp. 2-10, 1972.

[4] D. Barrick, "Remote sensing of sea state by radar," in Proceedings of the IEEE International Conference on Engineering in the Ocean Environment (Ocean '72), pp. 186-192, Newport, RI, USA, September 1972.

[5] D. E. Barrick, "Extraction of wave parameters from measured hf radar sea-echo doppler spectra," Radio Science, vol. 12, no. 3, pp. 415-424, 1977.
[6] B. J. Lipa and D. E. Barrick, "Least-Squares Methods for the Extraction of Surface Currents from CODAR Crossed-Loop Data: Application at ARSLOE,' IEEE Journal of Oceanic Engineering, vol. 8, no. 4, pp. 226-253, 1983.

[7] B. J. Lipa and D. E. Barrick, "Extraction of sea state from HF radar sea echo: mathematical theory and modeling," Radio Science, vol. 21, no. 1, pp. 81-100, 1986.

[8] D. Barrick, P. Lilleboe, B. Lipa, and L. Pederson, "Coastal surface-current mapping to $200 \mathrm{~km}$ with Long-Range SeaSondes," in Proceedings of the MTS/IEEE Conference and Exhibition (OCEANS '00), Conference Proceedings (Cat. No.00CH37158), vol. 1, pp. 555-558, Providence, RI, USA, 2000.

[9] D. Barrick and B. Lipa, "Using antenna patterns to improve the quality of SeaSonde HF radar surface current maps," in Proceedings of the IEEE 6th Working Conference on Current Measurement, (Cat. No.99CH36331), pp. 5-8, San Diego, Calif, USA, March 1999.

[10] T. Helzel, M. Kniephoff, and L. Petersen, "WERA: Remote ocean sensing for current, wave and wind direction," in Proceedings of the IEEE US/EU Baltic International Symposium (BALTIC '06), pp. 1-8, Klaipeda, Lithuania, May 2006.

[11] T. M. Hammond, C. B. Pattiaratchi, D. Eccles, M. J. Osborne, L. A. Nash, and M. B. Collins, "Ocean surface current radar (OSCR) vector measurements on the inner continental shelf," Continental Shelf Research, vol. 7, no. 4, pp. 411-431, 1987.

[12] K. J. Hickey, E. W. Gill, J. A. Helbig, and J. Walsh, "Measurement of ocean surface currents using a long-range, high-frequency ground wave radar," IEEE Journal of Oceanic Engineering, vol. 19, no. 4, pp. 549-554, 1994.

[13] W. Huang, S.-C. Wu, E. Gill, B.-Y. Wen, and J.-C. Hou, "HF radar wave and wind measurement over the Eastern China Sea," IEEE Transactions on Geoscience and Remote Sensing, vol. 40, no. 9, pp. 1950-1955, 2002. 
[14] Y.-W. Tian, B.-Y. Wen, and H. Zhou, "Measurement of high and low waves using dual-frequency broad-beam HF radar," IEEE Geoscience and Remote Sensing Letters, vol. 11, no. 9, pp. 15991603, 2014.

[15] C. Randell, D. Power, and R. Khan, "Ocean clutter characteristics for a coherent Doppler UHF radar," in Proceedings of the MTS/IEEE Conference and Exhibition (OCEANS '00), Conference Proceedings (Cat. No.00CH37158), vol. 3, pp. 1515-1520, Providence, RI, USA, 2000.

[16] C. C. Teague, D. E. Barrick, P. M. Lilleboe, R. T. Cheng, and C. A. Ruhl, "UHF RiverSonde observations of water surface velocity at Threemile Slough, California," in Proceedings of the IEEE International Geoscience and Remote Sensing Symposium (IGARSS '05), pp. 4383-4386, Seoul, South Korea, July 2005.

[17] C. C. Teague, D. E. Barrick, P. M. Lilleboe, R. T. Cheng, and C. A. Ruhl, "Long-term UHF RiverSonde river velocity observations at Castle Rock, Washington and Threemile Slough, California," in Proceedings of the IEEE/OES 8th Working Conference on Current Measurement Technology, pp. 85-89, June 2005.

[18] C. C. Teague, D. E. Barrick, P. M. Lilleboe, H. Roarty, D. Holden, and D. Goldinger, "Extended-range RiverSonde operation on the Hudson River," in Proceedings of the IEEE/OES/CWTM 10th Working Conference on Current, Waves and Turbulence Measurement (CWTM '11), pp. 78-80, Monterey, Calif, USA, March 2011.

[19] C. C. Teague, D. E. Barrick, P. M. Lilleboe, R. T. Cheng, P. Stumpner, and J. R. Burau, "Dual-RiverSonde measurements of two-dimensional river flow patterns," in Proceedings of the IEEE/OES/CMTC 9th Working Conference on Current Measurement Technology, pp. 258-263, Charleston, SC, USA, March 2008.

[20] Z. Ma, B. Wen, H. Zhou, C. Wang, and W. Yan, "UHF surface currents radar hardware system design," IEEE Microwave and Wireless Components Letters, vol. 15, no. 12, pp. 904-906, 2005.

[21] S. Wang, B. Wen, C. Wang, Z. Yan, K. Li, and J. Yang, "UHF surface dynamics parameters radar design and experiment," IEEE Microwave and Wireless Components Letters, vol. 24, no. 1, article 12, pp. 65-67, 2014.

[22] D. Jiang, B. Wen, C. Wang, K. Li, Z. Yan, and J. Yang, "A new type full digital uhf radar system design," IEICE Electronics Express, vol. 10, no. 11, pp. 1-6, 2013.

[23] K. Li, B. Wen, Y. Xu, J. Tan, J. Yang, and Y. Liu, "A novel UHF radar system design for river dynamics monitoring," IEICE Electronics Express, vol. 12, no. 4, 2015.

[24] R. O. Schmidt, "Multiple emitter location and signal parameter estimation," IEEE Transactions on Antennas and Propagation, vol. 34, no. 3, pp. 276-280, 1986.

[25] T.-J. Shan, M. Wax, and T. Kailath, "On spatial smoothing for direction-of-arrival estimation of coherent signals," IEEE Transactions on Acoustics, Speech, and Signal Processing, vol. 33, no. 4, pp. 806-811, 1985.

[26] R. T. Williams, S. Prasad, A. K. Mahalanabis, and L. H. Sibul, “An improved spatial smoothing technique for bearing estimation in a multipath environment," IEEE Transactions on Acoustics, Speech, and Signal Processing, vol. 36, no. 4, pp. 425-432, 1988. 


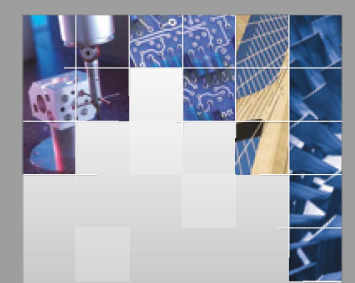

\section{Enfincering}
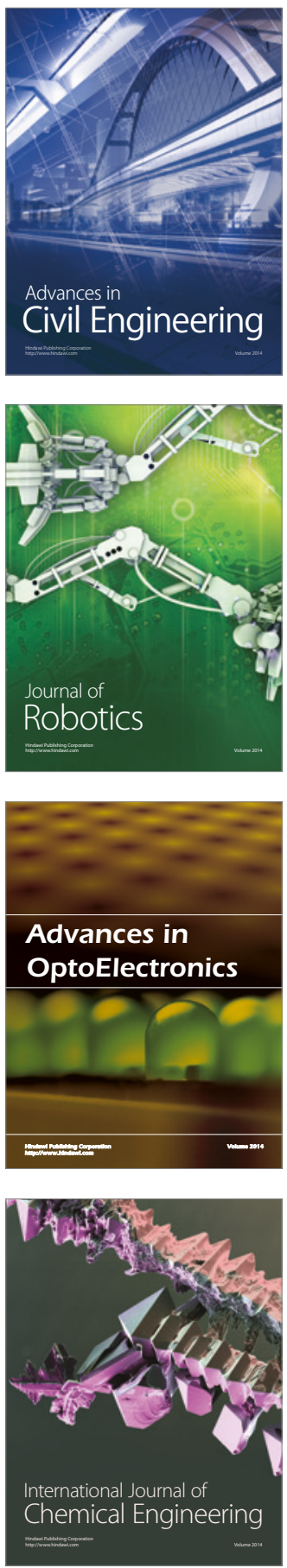

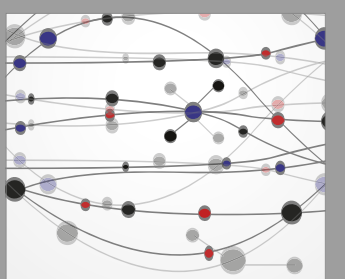

The Scientific World Journal

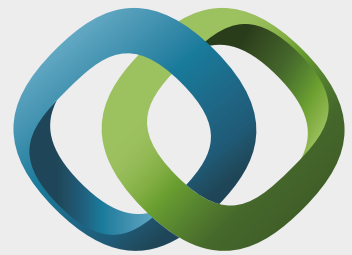

\section{Hindawi}

Submit your manuscripts at

https://www.hindawi.com
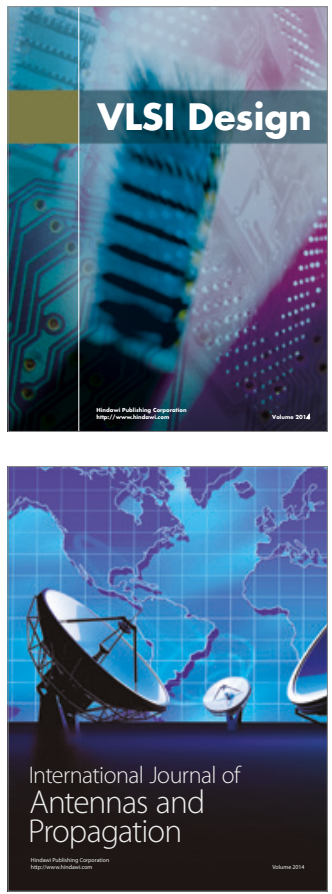

\section{Rotating}

Machinery
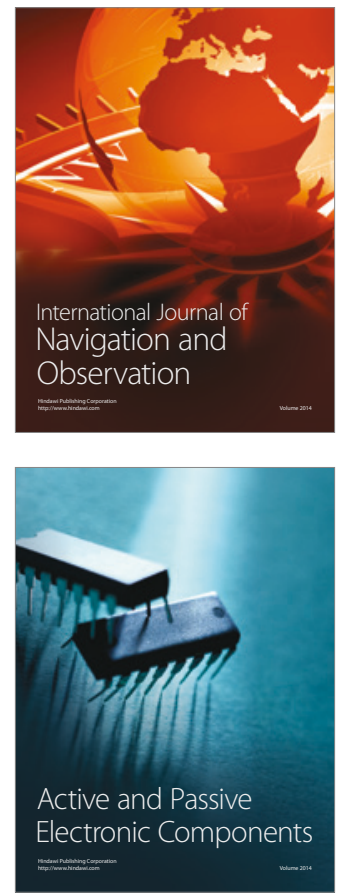
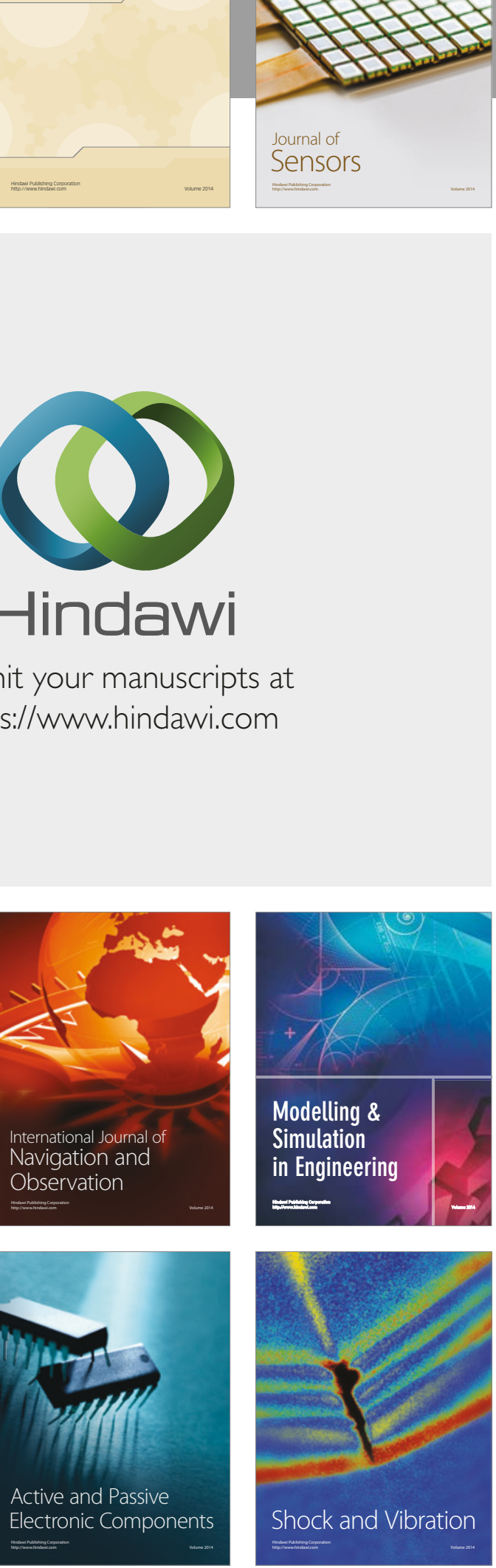
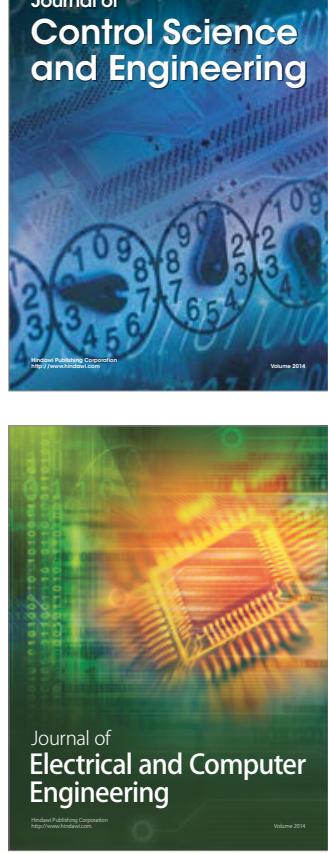

Distributed

Journal of

Control Science

and Engineering
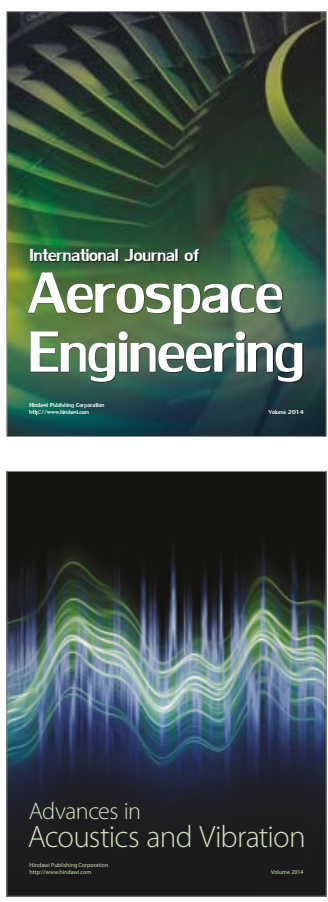

Sensor Networks 